\title{
Heterotopic Ossification: A Challenging Complication of Total Hip Arthroplasty: Risk Factors, Diagnosis, Prophylaxis, and Treatment
}

\author{
Paweł Lęgosz $\mathbb{D}^{1},{ }^{1}$ Maciej Otworowski ${ }^{D},{ }^{1}$ Aleksandra Sibilska, ${ }^{2}$ Krzysztof Starszak, \\ Daniel Kotrych, ${ }^{3}$ Adam Kwapisz, ${ }^{2}$ and Marek Synder ${ }^{2}$ \\ ${ }^{1}$ Department of Orthopaedics and Traumatology of the Musculoskeletal System, Infant Jesus Teaching Hospital, \\ Medical University of Warsaw, Warsaw, Poland \\ ${ }^{2}$ Clinic of Orthopaedics and Paediatric Orthopaedics Medical University of Lodz, Lodz, Poland \\ ${ }^{3}$ Department of Orthopaedics, Traumatology and Orthopaedic Oncology, Pomeranian Medical University of Szczecin, \\ Pomeranian Medical Academy Oncology Therapy and Research Center, Szczecin, Poland \\ Correspondence should be addressed to Maciej Otworowski; maciek.otworowski@gmail.com
}

Received 6 August 2018; Revised 2 February 2019; Accepted 24 February 2019; Published 16 April 2019

Academic Editor: Jianshu Li

Copyright (c) 2019 Paweł Łęgosz et al. This is an open access article distributed under the Creative Commons Attribution License, which permits unrestricted use, distribution, and reproduction in any medium, provided the original work is properly cited.

\begin{abstract}
Background. This review is intended to summarize the risk factors, classification, diagnosis, and treatment of heterotopic ossification (HO) of previously published studies. Results. Heterotopic ossification is a common complication of total hip arthroplasty. Its prevalence is not the same in all of the patient groups. Frequency of $\mathrm{HO}$ varies from 15 to $90 \%$. Hip ankylosis, male gender, and previous history of $\mathrm{HO}$ are said to be risk factors with a significant level. Diagnosis is based on a single AP radiograph: the Brooker classification that divides HO into four grades is the most commonly used. The confirmation test that can be used is a bone scan. A great amount of bone metabolic turnover markers have been tested, but none of them seems to be relevant in case of prevention or diagnosis of HO. The most effective prophylactic treatment is radiotherapy or administration of nonsteroidal antiinflammatory drugs. Over the years a lot of different RT protocols have been tested. Nowadays the most often used regimen is 7 Gy given postoperatively in a single dose. The most commonly prescribed drug in prophylaxis of HO is indomethacin. Also, the efficacy of ibuprofen and diclofenac was proven. Recently researchers focused on selective COX-2 inhibitors. They appear to be as effective as nonselective NSAIDs having less side effects. The one and only treatment of HO is a revision arthroplasty.
\end{abstract}

\section{Introduction}

Heterotopic ossification (HO) (Figure 1) is a relatively common complication of hip arthroplasty procedures. According to data from several studies, their frequency varies from 15 to $90 \%$ depending on the investigated group of patients [113]. The latest meta-analysis from 2015 presented the average frequency of their occurrence at the level of 30\% [14]. Considering the epidemiology of hip arthroplasty ossifications affect a significant percentage of patients. These figures are likely to steadily increase until the development of specific treatment strategies. None of the numerous international or national orthopaedic associations have yet developed guidelines for the prevention and management of patients with existing heterotopic ossifications.
This is an extremely important challenge, as ossifications may destroy the healing effect of surgery, limiting to a large extent of range of motions in the hip joint and additionally exposing the patient to subsequent surgical treatment, revision arthroplasty.

\section{Methodology}

A search was performed on PubMed, Embase, and Cochrane Central Register. It was conducted using key word "heterotopic ossification" combined with either "THR", "total hip replacement", "THA", "total hip arthroplasty", "NSAIDs", "risk factors", "radiotherapy", "radiation", "marker", or "markers". Also, the search of references in included studies was performed. There were no restrictions in language or 


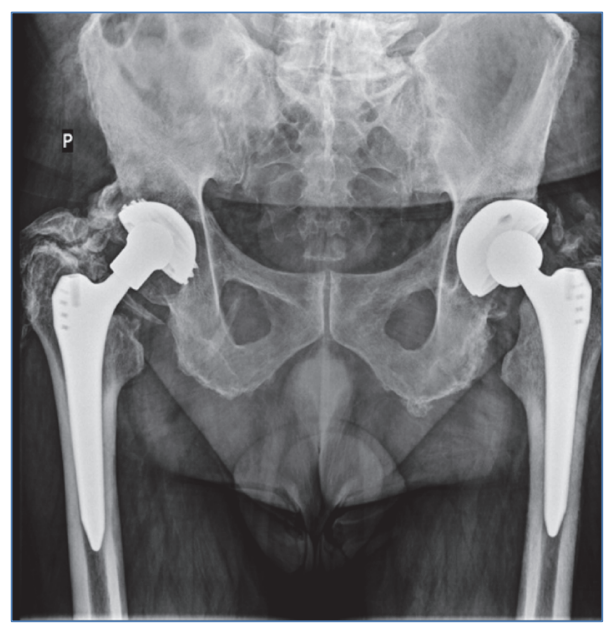

(a)

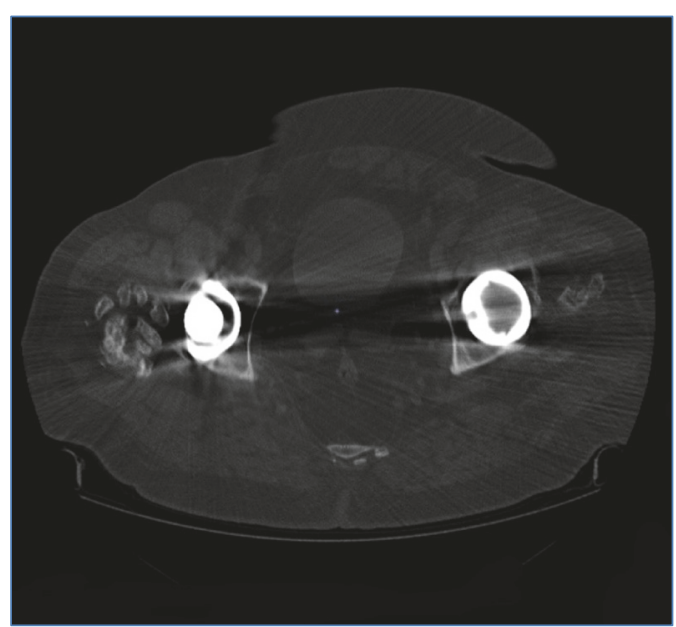

(b)

FIGURE 1: Heterotopic ossification visible on an AP X-ray (a) and on a computed tomography scan (b) around right hip. It is a complete hip ankylosis. HO like this can completely sabotage functional outcomes of THR limiting the range of motion in all planes. This is why using right prophylaxis is so crucial (from the Department of Orthopaedics and Traumatology of the Musculoskeletal System, Infant Jesus Teaching Hospital, Medical University of Warsaw records).

date of publication. Studies were excluded from our analysis if there were abstracts, letters, case reports, case series, guidelines, or irrelevant significance for our study topic. We identified 4628 articles. Of these articles, 836 were removed due to duplicate reportage, and 3675 were excluded based on the titles and abstracts. The remaining 117 articles were accessed for the full text and screened for further assessment. Finally, we included 63 articles in our review.

\section{Risk Factors}

A number of studies demonstrating the existence of potential risk factors for heterotopic ossifications after hip arthroplasty have been found in the literature [3, 4, 19-24].

In the recent meta-analysis it was estimated that male sex, cemented prosthesis, bilateral hip joint arthroplasty procedure, ankylosing spondylitis, and hip joint ankylosis are associated with increased risk of nonarticular ossification [14]. In addition, the above factors have been divided into those with significant and moderate level of risk of HO. The first group included hip ankylosis and male gender. The group with a moderate level included cemented type of prosthesis, bilateral procedure, and ankylosing spondylitis.

According to the same study, the only factor that is said to decrease $\mathrm{HO}$ is rheumatoid arthritis [Table 2].

In addition, it has been demonstrated that surgeries due to femoral neck fracture, degenerative disease, previous hip fracture, hypertrophic type of osteoarthritis, and age are not associated with an increased risk of heterotopic ossification.

There have been studies evaluating the assessment of the impact of revision surgery, lateral approach in hip arthroplasty, BMI, bone grafting, and trochanteric osteotomy on the potential occurrence of ossification but even if they reported a positive correlation they require further research [14].

\section{Classification}

The most commonly used method of classification is Brooker classification based only on a single X-ray image in the anteroposterior (AP) projection $[21,25,26]$.

Usually, ossifications that develop after surgery are visible in the radiological examination after 4-6 weeks $[2,5,6,8,12$, 13, 27-30].

The Brooker classification divides the heterotopic ossifications into four grades (Figure 2):

I - described as islands of bone within the soft tissues about the hip;

II - consisting of bone spurs originating from the pelvis or proximal end of the femur, leaving at least $1 \mathrm{~cm}$ between opposing bone surfaces;

III - consisting of bone spurs originating from the pelvis or proximal end of the femur, reducing the space between opposing bone surfaces to less than $1 \mathrm{~cm}$;

IV - hip joint ankylosis $[25,26]$.

Types III and IV are referred to as clinically relevant [12, $21,30,31]$.

\section{Diagnosis and Decision Making}

The level of alkaline phosphatase in serum increases during tissue injuries; therefore its predictive value in heterotopic ossifications after hip arthroplasty is doubtful [32]. However, it is still used in some clinical conditions [32]. Over the years, many attempts have been made to determine alkaline phosphatase in serum but it seems that this method is not specific without clear evidence for its predictive value. Both Mollan and Kjaersgaard did not report any significant correlation when assessing the dependence of alkaline phosphatase levels on the occurrence of heterotopic ossifications [33-36].

Wilkinson et al. tried to find alternative bone metabolic turnover markers that could be used in the diagnosis of 


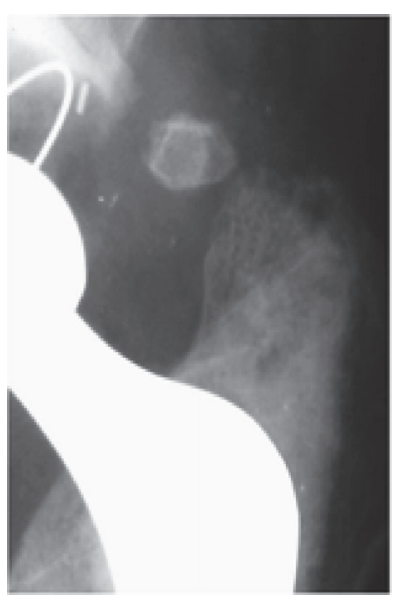

(a)

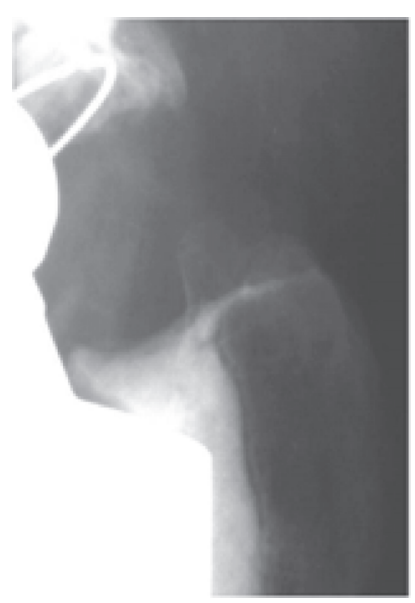

(b)

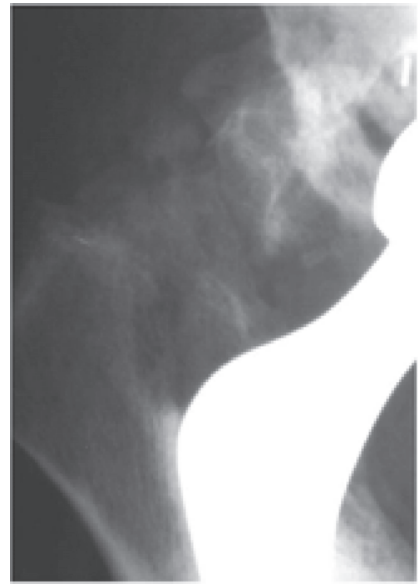

(c)

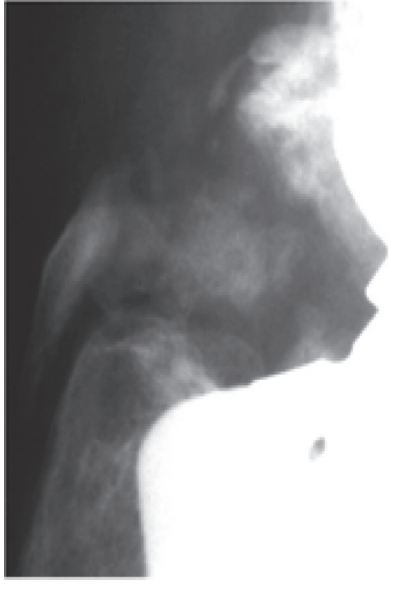

(d)

Figure 2: The presence of HO Graded in Brooker Classification as I (a), II (b), III (c), and IV (d) on a follow-up after THR (from the Clinic of Orthopaedics and Paediatric Orthopaedics Medical University of Lodz records).

heterotopic ossifications in patients after hip arthroplasty. According to their study, C telopeptide of type I-collagen (CTX-1) is potentially useful marker, which increases its concentration in the first postoperative week by $42 \%$ and shows a sensitivity of $89 \%$ and specificity of $82 \%$ in the prediction of the diagnosis of ossifications in the 26th week after surgery [33]. Unfortunately, such findings are not sufficient to assess the validity of routine CTX-1 measurements, as indomethacin therapy should be implemented on the first postoperative day, and radiotherapy is most effective if it is performed on the fifth postoperative day $[7,17,28,37,38]$.

Based on Wilkinson's research, we can reject $\mathrm{N}$-terminal propeptide of type I-procollagen (PINP) and osteocalcin (OC) from potential testings, as their increased correlation with $\mathrm{HO}$ occur too late to implement effective prophylaxis. Moreover, the levels of N-telopeptide of type I-collagen (NTX-1) and deoxypyridinoline (DPD) were not correlated at all with the presence of ossifications [33].

Bone metabolic turnover markers have also general diagnostic limitations. Their level fluctuates in relation to gender, coexisting diseases and some are prone to daily or seasonal fluctuations, which makes them difficult to use as a simple diagnostic tool [33].

In papers heterotopic ossification symptoms include swelling, redness, and pain as subjective symptoms. Therefore, symptoms of ossification may imitate deep vein thrombosis in the lower limbs or cellulitis. Unfortunately, none of these studies are supported by the relevant figures $[12,32,36$, 39-41].

Scintigraphy is the most sensitive method in diagnosing HO $[32,36,42]$. Changes in the X-ray images may be preceded by the changes in scintigraphy with a time of 4 to 6 weeks [41].

The formerly used radiopharmaceutical was strontium, currently 99mTc; pyrophosphate is used [22, 41, 42]. Pyrophosphate is a calcium metabolism regulator; it accumulates in places where the metabolic turnover of calcium is increased [22].
Scintigraphy is based on the administration of a radiopharmaceutical and the subsequent production of a series of scans that will provide information during three phases: a dynamic blood flow, blood accumulation, and the accumulation of a radiopharmaceutical in the bone [41].

Scintigraphy is particularly effective in determining the maturity of heterotopic ossifications and planning their operational removal $[39,42]$. The maturity of ossification is indicated by a decrease in radiopharmaceutical uptake when comparing the results of subsequent scintigraphic tests [39].

Schurch et al. conducted a study to evaluate the usefulness of prostaglandin E2 (PGE-2) measurements in urine to predict the formation of HO. They reported increased level of PGE-2 in urine in patients with developing ossification. The authors recommended examining 24-hour PGE-2 level once a week for a period of 3 to 4 months. The increase in this excretion was expected to indicate the development of heterotopic ossification [40].

Orzel et al., in their retrospective analysis of 24 patients' ossifications, showed that calcium levels in serum had decreased below the reference level in 23 cases. The reduction occurred on average during fifth day and lasted on average ten days [36]. It seems that it would not be clinically useful to use this as a diagnostic test either, due to the late outcomes compared to the optimal time after surgery to undertake prophylaxis.

\section{Prophylaxis of Heterotopic Ossification: Methods and Their Effectiveness}

(1) Radiotherapy (RT). It is estimated that the prevalence of $\mathrm{HO}$ should not be greater than $10 \%$ after the radiation prophylactic treatment $[43,44]$.

Over the years many RT regimens have been tested. The first observation was published by a team from Mayo Clinic. They used fractionated RT ( $2 \times 10$ Gy) [29]. Then researchers tried to find the lowest effective dose [5, 17, 18, 28, 37, 45-47]. 
In a meta-analysis Milakovic et al. found no significant differences in a $\mathrm{HO}$ prevalence between the patients treated with banana equivalent dose (BED) $>2500 \mathrm{cGy}$ and the patients treated with BED doses <2500 cGy [2]. Healy et al. reported that radiating the hip with a single dose of $550 \mathrm{cGy}$ is less effective than with a 700 cGy [37].

The difference in $\mathrm{HO}$ occurrence was so significant that the researchers advised not to use that protocol again. It seems that Finegorth et al. found the boundary of an effective radiation protocol with a 6 Gy given postoperatively [17].

Nowadays the most often prescribed is a single dose radiation of $700 \mathrm{~Gy}[2]$.

Also, the effectiveness of preoperative radiation has been measured [3, 19, 27, 43]. Radiation prescribed before the procedure limits the patient discomfort and reduces the risk of hip dislocation $[3,19,48]$. Gregoritch et al. concluded that there is no difference between the treatment given 6 hours before the procedure and the treatment given 72 hours postoperatively [48]. Milakovic and Seegenschmiedt in a large, multicenter study showed no differences between radiation prescribed before the operation and after the operation $[2,18]$. However, it appears that there is less indications for preoperative radiation than for postoperative radiation. The preoperative regimens are ineffective if the patient is operated on $\mathrm{HO}$ graded as III or IV in Brooker classification $[2,18]$.

The most important factor in a prophylactic radiation treatment is time. Seegenschmiedt concluded that it must not be given earlier than 8 hours before the procedure and later than 72 hours after the procedure [18]. The other authors are in agreement that hip should be radiated within 5 days after the operation $[5,6,28,38,44,45,49]$.

Finally, the fractionated radiation has been compared with a single dose radiation. Konsi et al. in a randomized study showed the same efficacy of a single dose radiation compared to a fractioned one [38]. Milakovic et al. concluded that a single dose radiation was associated with a higher prevalence of $\mathrm{HO}$, but only in lower grades of Brooker classification [2].

RT is not only effective, but safe. Sheybani et al. analyzed records of over 3500 patients who underwent a THR [50]. They concluded that there is no elevation of the malignancy risk after the radiation prophylaxis treatment.

\section{(2) Relevance of Using Medications}

(a) Nonsteroidal Anti-Inflammatory Drugs (NSAIDs). The most commonly used drug in $\mathrm{HO}$ prophylaxis is indomethacin. It is probable mechanism of stopping the bone formation is by inhibiting the inflammation process [4].

Schmidt et al. in a prospective, double-blind, randomized study proved the effectiveness of indomethacin in HO prevention [15]. It was given 3 times a day in a $25 \mathrm{mg}$ dose for 6 weeks after the procedure. No ossification was graded greater than I in Brooker classification. Kjaersgaard in his study used the same dose as Schmidt, but prescribed it for 2 weeks [51]. It was as effective as the 6-week therapy.

Another drug whose efficacy has been proved is ibuprofen. Elmsted et al. showed its effectiveness compared to a placebo [52]. Sodemanna et al. showed no difference in $\mathrm{HO}$ occurrence between the group treated with indomethacin (50 $\mathrm{mg} / \mathrm{d})$ and the group treated with ibuprofen $(3 \times 400 \mathrm{mg} / \mathrm{d})$ for the same time (20 days) [53].

It appears that the shortest possible treatment time with nonselective oral NSAIDs is one week [7]. It should not be started before the procedure, because ineffectiveness of such intervention has been proved and it elevates the risk of an excessive bleeding during the procedure [7].

Pritchett studied the efficacy of ketorolac in a prospective, double-blind, randomized study [54]. It was administered in injections. The protocol started during the arthroplasty and ended $48 \mathrm{~h}$ after the procedure. None of the patients developed clinically significant HO.

It appears that there are no big differences between the two most studied prophylactic treatments. Kienapfel et al. conducted a study that compared indomethacin given in a dose of 2x $50 \mathrm{mg}$ for 42 days with a single dose $600 \mathrm{~Gy}$ postoperative radiation. The treatments were equally effective in preventing $\mathrm{HO}[4]$.

Knells et al. conducted prospective study comparing indomethacin with acetylsalicylic acid and radiotherapy. They concluded that the most effective prophylactic treatment for the general population is indomethacin prescribed in a dose of $250 \mathrm{mg}$ daily for 14 days starting on the first postoperative day. The patients with a higher chance of developing $\mathrm{HO}$ or with the contradictions for nonselective NSAIDs should be qualified for RT [55].

Kolbl et al. compared preoperative radiation (7 Gy 16$20 \mathrm{~h}$ before the procedure) and diclofenac $(2 \times 75 \mathrm{mg}$ for 14 days starting at the 1st postoperative day). They showed no difference in lowering the clinically significant $\mathrm{HO}$ occurrence, although the overall prevalence of $\mathrm{HO}$ was lower in diclofenac group [3].

The only prospective study evaluating efficacy of combined therapy conducted Pakos et al. [56]. They compared combined prophylactic therapy (radiotherapy + indomethacin) with indomethacin alone. There were two prospective groups: patients older than 55 y.o. treated with a single dose 7 Gy radiation and indomethacin given in a dose of $75 \mathrm{mg}$ for 15 days; patients younger than 55 y.o. treated with indomethacin given in the same dosage and continued for the same amount of time. To reduce the influence of age on the outcomes the historic group was created: it consisted of patients older than 55 y.o. treated with indomethacin in the same dosage continued for the same amount of time. HO was less frequent in the first group than in the other two ( $8 \%$ versus $27 \%$ versus $26 \%)$.

Selective cyclooxygenase-2 (COX-2) inhibitors are a very attractive form of treatment, because they show less gastrointestinal side effects and lack interaction with platelets aggregation [8, 9, 11, 12, 23, 57]. However, it should be mentioned that studies showed elevated cardiovascular risk during the treatment with a selective COX-2 inhibitors [8, 9, $11,12,58]$.

The elevated cardiovascular risk was observed after 6 months of treatment (also, 12 or even 18 months were mentioned in other studies), period way longer than prophylactic treatment time after total hip replacement (THR) $[12,13]$. 
Rofecoxib and celecoxib has been the most studied agents and proved reliable [8].

Lavernia et al. proved effectiveness of etoricoxib compared to historical group that did not take any prophylaxis at all [9]. Patients received etoricoxib in a dosage of 200 mg twice daily for two weeks. Walther et al. reported HO 6 months after the procedure in $30 \%$ of the patients treated with a rofecoxib (2 out of 137 were graded as II in Brooker classification) [57]. At a dosage of $25 \mathrm{mg}$ continued for 2 weeks starting on the first or second postoperative day rofecoxib showed the effectiveness as a diclofenac described in a literature at a dosage of $100-150 \mathrm{mg}$. The study conducted by Winkler et al. gave us even more information about etoricoxib. It was a prospective, double-blind, randomized study that compared etoricoxib $(90 \mathrm{mg} / \mathrm{d})$ and diclofenac (70 mg/d) both given for 9 days, starting the first day after the procedure [8]. No difference was found in $\mathrm{HO}$ occurrence.

Finally, the very conclusive results came with both Grohs and van der Heide studies [10,58]. They compared rofecoxib with indomethacin. The rofecoxib group in Groh's study was given it in a dosage of $25 \mathrm{mg}$ daily for 7 days and in van der Heide's $25 \mathrm{mg}$ twice daily for 7 days. The indomethacin group was given it in a dosage of $50 \mathrm{mg}$ twice daily in the first study and thrice in second. Grohs reported lower occurrence of $\mathrm{HO}$ in rofecoxib group. Also, he reported greater prevalence of $\mathrm{HO}$ graded as III or IV in Brooker classification. Van der Heide showed no significant difference between two groups in $\mathrm{HO}$ occurrence ( $87 \%$ versus $85 \%$ ).

Oni et al. conducted prospective study with celecoxib [12]. Patients had taken it in a dosage of $200 \mathrm{mg}$ daily for 6 weeks, starting at the first postoperative day. The control group consisted of patients that had not taken any prophylaxis. HO was less frequent and the Harris Hip Score (HHS) score was higher in the celecoxib group, although as much as 10 percent of the ossifications in this group were graded as III in Brooker classification. Romano compared celecoxib (2x200 mg) with indomethacin $(2 \times 500 \mathrm{mg})$; both were prescribed for 20 days starting the first postoperative day [23]. After the year, in the group treated with celecoxib they reported lower occurrence of $\mathrm{HO}(17,5 \%$ versus $14,3 \%)$; also in the celecoxib group there were less discontinuations due to gastrointestinal side effects (2\% versus $8,4 \%)$.

Saudan et al. compared celecoxib (2x200 mg) and ibuprofen $(3 \times 400 \mathrm{mg})$. Celecoxib turned out to be more effective in preventing $\mathrm{HO}$ than ibuprofen [13].

Xue et al. conducted a meta-analysis of randomized studies that compared NSAIDs with selective COX-2 inhibitors [11]. They found no significant differences in overall $\mathrm{HO}$ prevalence and in clinically significant ossifications prevalence. Moreover, the patients treated with selective COX-2 inhibitors showed less discontinuations due to gastrointestinal side effects.

Another meta-analysis by Shun Lin et al. showed better outcomes in HO prevention after NSAIDs prophylaxis treatment compared with placebo. In this study, researchers also measured the discontinuation of the therapy due to gastrointestinal side effects and compared it between groups treated with nonselective NSAIDs and selective COX-2 inhibitors.
The discontinuation was more frequent in the nonselective NSAIDs group.

(b) Diphosphonates. The prophylaxis of $\mathrm{HO}$ that was proven to be ineffective is treatment with diphosphonates $[6,20,44$, $46,47,49]$. This therapy only delays development of HO. Diphosphonates inhibit hydroxyapatite crystals growth, but has no effect whatsoever on the production of the osteoid matrix $[6,20,44,47,59]$. After the therapy is ended previously created scaffold begins to calcify and therefore it could be visualized on radiographs [20,44, 47, 59]. Thomas et al. compared two patients' groups that took diphosphonates starting 2-4 weeks before the operation and continuing it for 3 weeks after the procedure [20]. The first group took them in a dosage of $10 \mathrm{mg} / \mathrm{kg}$, and the second in a dosage of $20 \mathrm{mg} / \mathrm{kg}$. In both groups diphosphonates were equally ineffective in preventing $\mathrm{HO}$.

Bijovet et al. also proved inefficacy of diphosphonates in HO prophylaxis by conducting a prospective study [59]. Patients started the therapy 6 weeks before the procedure and ended it 6 or 12 weeks after the procedure. The prescribed dose was $20 \mathrm{mg} / \mathrm{kg}$ given daily. On the radiographic follow-up during the treatment only $10 \%$ of the patients revealed HO. However, 2 to 3 months after the termination of the therapy $\mathrm{HO}$ was diagnosed in $60 \%$ of the patients.

\section{Treatment of Manifested HO}

Grades I and II HO may not need any treatment unless they become symptomatic or functionally disabling. The gold standard therapy for grades III and IV $\mathrm{HO}$ is a revision arthroplasty and surgical resection of the ossification $[5,6$, $13,32,35,36,42,46]$. To lower the risk of intraoperative complications such as excessive bleeding and postoperative complications such as recurrence the procedure must be performed when the $\mathrm{HO}$ is mature [32, 42]. Also, it should be kept in mind that the strongest risk factor of $\mathrm{HO}$ development is the previous history of $\mathrm{HO}$, so prophylaxis treatment must be administered after the operation [14]. It has been proven that incorporating of appropriate care managers into health system who work directly with individual patients helps them with lifestyle changing, monitors their condition, and ultimately influences a better compliance with the suggested recommendations [60].

\section{Conclusion}

$\mathrm{HO}$ is one of the most common complications after THA. Until now, no algorithm for detection and treatment has been developed. A series of papers agree on risk factors and we collected those in Table 2. Many biochemical markers have been measured, but none of them have been widely used in clinical practice. Scintigraphy seems to be the most sensitive method in diagnosing but $\mathrm{X}$ rays are the most frequently used. As regards prophylaxis, the effects of radiotherapy (pre/postoperatively) and pharmacotherapy have been proven. NSAIDs and COX2 inhibitors are commonly used. $\mathrm{HO}$ is a problem for a large number of patients and 
TABLE 1: Summary of the most relevant finding in literature.

\begin{tabular}{|c|c|c|}
\hline Author & Year & Results \\
\hline Schmidt et al. [15] & 1988 & $\begin{array}{l}\text { Indomethacin is especially recommended for patients } \\
\text { who are at high risk for HO. }\end{array}$ \\
\hline Wright et al. [16] & 1994 & $\begin{array}{l}\text { The severity of HO did not correlate with the HHS; the } \\
\text { relationship between HO and range of motion (ROM) } \\
\text { indicates that the Brooker index is a valid measurement. }\end{array}$ \\
\hline Fingeroth et al. [17] & 1995 & $\begin{array}{c}\text { A single dose of } 6 \mathrm{~Gy} \text { of radiation given within the first } \\
3 \text { postoperative days provides effective prophylaxis } \\
\text { against } \mathrm{HO} \text {. }\end{array}$ \\
\hline $\begin{array}{l}\text { Seegenschmiedt et al. } \\
{[18]}\end{array}$ & 2001 & $\begin{array}{l}\text { Both preoperative (within } 24 \mathrm{~h} \text { ) and postoperative RT } \\
\text { (within } 72 \mathrm{~h} \text { ) are effective in preventing HO after hip } \\
\text { surgery. }\end{array}$ \\
\hline Saudan et al. [13] & 2007 & $\begin{array}{l}\text { Celecoxib was more effective than ibuprofen in } \\
\text { preventing heterotopic bone formation after total hip } \\
\text { replacement. }\end{array}$ \\
\hline Xu et al. [11] & 2014 & $\begin{array}{l}\text { Considering the side effects of nonselective NSAIDs, } \\
\text { selective COX-2 inhibitors were recommend for the } \\
\text { prevention of HO after THA. }\end{array}$ \\
\hline Lavernia et al. [9] & 2014 & $\begin{array}{l}\text { A short course of celecoxib for pain aids in the } \\
\text { prevention of HO after primary THR. }\end{array}$ \\
\hline Winkler et al. [8] & 2016 & $\begin{array}{l}\text { Etoricoxib and diclofenac are equally effective for oral } \\
\text { HO prophylaxis after primary cementless THA when } \\
\text { given for nine peri-operative days. }\end{array}$ \\
\hline
\end{tabular}

TABLE 2: Risk factors of heterotopic qssification.

\begin{tabular}{lc}
\hline Level of risk & Factor \\
\hline High & $\begin{array}{c}\text { Hip ankylosis, male gender, } \\
\text { previous history of HO. }\end{array}$ \\
\hline Medium & $\begin{array}{c}\text { Cemented type of } \\
\text { prosthesis, bilateral } \\
\text { procedure, ankylosing } \\
\text { spondylitis. }\end{array}$ \\
\hline Low & Rheumatoid arthritis \\
\hline
\end{tabular}

further research should be performed. The most relevant findings in literature are gathered in Table 1.

\section{Conflicts of Interest}

The authors declare that they have no conflicts of interest.

\section{References}

[1] S. L. Kan, B. Yang, G. Z. Ning et al., "Nonsteroidal antiinflammatory drugs as prophylaxis for heterotopic ossification after total hip arthroplasty," Medicine, vol. 94, no. 18, p. e828, 2015.

[2] M. Milakovic, M. Popovic, S. Raman, M. Tsao, H. Lam, and E. Chow, "Radiotherapy for the prophylaxis of heterotopic ossification: A systematic review and meta-analysis of randomized controlled trials," Radiotherapy \& Oncology, vol. 116, no. 1, pp. 4-9, 2015.

[3] O. Kölbl, D. Knelles, T. Barthel, F. Raunecker, M. Flentje, and J. Eulert, "Preoperative irradiation versus the use of nonsteroidal anti-inflammatory drugs for prevention of heterotopic ossification following total hip replacement: the results of a randomized trial," International Journal of Radiation Oncology, Biology, Physics, vol. 42, no. 2, pp. 397-401, 1998.

[4] H. Kienapfel, M. Koller, A. Wüst et al., "Prevention of heterotopic bone formation after total hip arthroplasty: A prospective randomised study comparing postoperative radiation therapy with indomethacin medication," Archives of Orthopaedic and Trauma Surgery, vol. 119, no. 5-6, pp. 296-302, 1999.

[5] M. H. Seegenschmiedt, A. R. Goldmann, R. Wölfel, D. Hohmann, H. Beck, and R. Sauer, "Prevention of heterotopic ossification (HO) after total hip replacement: randomized high versus low dose radiotherapy," Radiotherapy \& Oncology, vol. 26, no. 3, pp. 271-274, 1993.

[6] I. MacLennan, H. M. Keys, C. McCollister Evarts, and P. Rubin, "Usefulness of postoperative hip irradiation in the prevention of heterotopic bone formation in a high risk group of patients," International Journal of Radiation Oncology, Biology, Physics, vol. 10, no. 1, pp. 49-53, 1984.

[7] O. S. Nilsson and P.-E. Persson, "Heterotopic bone formation after joint replacement," Current Opinion in Rheumatology, vol. 11, no. 2, pp. 127-131, 1999.

[8] S. Winkler, H.-R. Springorum, T. Vaitl et al., "Comparative clinical study of the prophylaxis of heterotopic ossifications after total hip arthroplasty using etoricoxib or diclofenac," International Orthopaedics, vol. 40, no. 4, pp. 673-680, 2016.

[9] C. J. Lavernia, J. S. Contreras, J. M. Villa, and M. D. Rossi, "Celecoxib and heterotopic bone formation after total hip arthroplasty," The Journal of Arthroplasty, vol. 29, no. 2, pp. 390392, 2014.

[10] J. G. Grohs, M. Schmidt, and A. Wanivenhaus, "Selective COX-2 inhibitor versus indomethacin for the prevention of heterotopic ossification after hip replacement: a double-blind randomized trial of 100 patients with 1-year follow-up," Acta Orthopaedica, vol. 78, no. 1, pp. 95-98, 2007. 
[11] B.-G. Xu, D.-T. Xue, X.-H. Wang, and S.-G. Yan, "Selective COX-2 inhibitor versus nonselective COX-1 and COX-2 inhibitor in the prevention of heterotopic ossification after total hip arthroplasty: a meta-analysis of randomised trials," China Journal of Orthopaedics And Traumatology, vol. 27, no. 7, pp. 609-614, 2014.

[12] J. K. Oni, J. R. Pinero, B. M. Saltzman, and F. F. Jaffe, "Effect of a selective COX-2 inhibitor, celecoxib, on heterotopic ossification after total hip arthroplasty: a case-controlled study," Hip International, vol. 24, no. 3, pp. 256-262, 2014.

[13] M. Saudan, P. Saudan, T. Perneger, N. Riand, A. Keller, and P. Hoffmeyer, "Celecoxib versus ibuprofen in the prevention of heterotopic ossification following total hip replacement: a prospective randomised trial," The Journal of Bone \& Joint Surgery, vol. 89, no. 2, pp. 155-159, 2007.

[14] Y. Zhu, F. Zhang, W. Chen, Q. Zhang, S. Liu, and Y. Zhang, "Incidence and risk factors for heterotopic ossification after total hip arthroplasty: a meta-analysis," Archives of Orthopaedic and Trauma Surgery, vol. 135, no. 9, pp. 1307-1314, 2015.

[15] S. A. Schmidt, P. Kjaersgaard-Andersen, W. N. Pedersen, S. S. Kristensen, P. Pederson, and B. J. Nielsen, "The use of indomethacin to prevent the formation of heterotopic bone after total hip replacement. A randomized, double-blind clinical trial," The Journal of Bone \& Joint Surgery, vol. 70, no. 6, pp. 834838, 1988.

[16] J. G. Wright, E. Moran, and E. Bogoch, "Reliability and validity of the grading of heterotopic ossification," The Journal of Arthroplasty, vol. 9, no. 5, pp. 549-553, 1994.

[17] R. J. Fingeroth and A. Q. Ahmed, "Single dose 6 Gy prophylaxis for heterotopic ossification after total hip arthroplasty," Clinical Orthopaedics and Related Research, vol. 317, pp. 131-140, 1995.

[18] M. H. Seegenschmiedt, H. Makoski, and O. Micke, "Radiation prophylaxis for heterotopic ossification about the hip joint-a multicenter study," International Journal of Radiation Oncology, Biology, Physics, vol. 51, no. 3, pp. 756-765, 2001.

[19] V. D. Pellegrini Jr. and S. J. Gregoritch, "Preoperative irradiation for prevention of heterotopic ossification following total hip arthroplasty," The Journal of Bone \& Joint Surgery, vol. 78, no. 6, pp. 870-881, 1996.

[20] B. J. Thomas and H. C. Amstutz, "Results of the administration of diphosphonate for the prevention of heterotopic ossification after total hip arthroplasty," Journal of Bone and Joint SurgeryAmerican Volume, vol. 67, no. 3, pp. 400-403, 1985.

[21] A. Schuh and G. Zeiler, "The modified brooker classification for evaluation of heterotopic ossifications in total hip replacement," Zentralblatt für Chirurgie, vol. 130, no. 4, pp. 293-296, 2005.

[22] Y. Suzuki, K. Hisada, and M. Takeda, "Demonstration of myositis ossificans by (99m)Tc pyrophosphate bone scanning," Radiology, vol. 111, no. 3, pp. 663-664, 1974.

[23] C. L. Romanò, D. Duci, D. Romanò, M. Mazza, and E. Meani, "Celecoxib versus indomethacin in the prevention of heterotopic ossification after total hip arthroplasty," The Journal of Arthroplasty, vol. 19, no. 1, pp. 14-18, 2004.

[24] D. Kotrych and R. Król, "Dysphagia in Forestier's disease," Ortopedia Traumatologia Rehabilitacja, vol. 6, no. 1, pp. 99-102, 2004.

[25] A. F. Brooker, J. W. Bowerman, R. A. Robinson, and L. H. Riley Jr., "Ectopic ossification following total hip replacement. Incidence and a method of classification," The Journal of Bone and Joint Surgery, vol. 55, no. 8, pp. 1629-1632, 1973.

[26] K. T. Hug, T. B. Alton, and A. O. Gee, "In brief: classifications in brief: brooker classification of heterotopic ossification after total hip arthroplasty," Clinical Orthopaedics and Related Research, vol. 473, no. 6, pp. 2154-2157, 2015.

[27] M. H. Seegenschmiedt, L. Keilholz, P. Martus et al., "Prevention of heterotopic ossification about the hip: Final results of two randomized trials in 410 patients using either preoperative or postoperative radiation therapy," International Journal of Radiation Oncology, Biology, Physics, vol. 39, no. 1, pp. 161-171, 1997.

[28] G. J. van der Werf, N. G. van Hasselt, and A. J. Tonino, "Radiotherapy in the prevention of recurrence of periarticular ossification in total hip prostheses," Archives of Orthopaedic and Trauma Surgery, vol. 104, no. 2, pp. 85-88, 1985.

[29] M. B. Coventry and P. W. Scanlon, "The use of radiation to discourage ectopic bone. A nine-year study in surgery about the hip," The Journal of Bone \& Joint Surgery, vol. 63, no. 2, pp. 201$208,1981$.

[30] G. I. Vasileiadis, D. F. Amanatullah, J. R. Crenshaw, M. J. Taunton, and K. R. Kaufman, "Effect of heterotopic ossification on hip range of motion and clinical outcome," The Journal of Arthroplasty, vol. 30, no. 3, pp. 461-464, 2015.

[31] L. Ahrengart, "Periarticular heterotopic ossification after total hip arthroplasty. Risk factors and consequences," Clinical Orthopaedics and Related Research, no. 263, pp. 49-58, 1991.

[32] D. Shehab, A. H. Elgazzar, and B. D. Collier, "Heterotopic ossification mimicking infection scintigraphic evaluation," Journal of Clinical Nuclear Medicine, vol. 43, no. 3, pp. 346-353, 2002.

[33] J. M. Wilkinson, I. Stockley, A. J. Hamer, N. A. Barrington, and R. Eastell, "Biochemical markers of bone turnover and development of heterotopic ossification after total hip arthroplasty," Journal of Orthopaedic Research, vol. 21, no. 3, pp. 529-534, 2003.

[34] R. A. B. Mollan, "Serum alkaline phosphatase in heterotopic para-articular ossification after total hip replacement," The Journal of Bone \& Joint Surgery (British Volume), vol. 61, no. 4, pp. 432-434, 1979.

[35] P. Kjaersgaard-Andersen, P. Pedersen, S. S. Kristensen, S. A. Schmidt, and N. W. Pedersen, "Serum alkaline phosphatase as an indicator of heterotopic bone formation following total hip arthroplasty," Clinical Orthopaedics and Related Research, no. 234, pp. 102-109, 1988.

[36] J. A. Orzel and T. G. Rudd, "Heterotopic bone formation: clinical, laboratory, and imaging correlation," Journal of Nuclear Medicine, vol. 26, no. 2, pp. 125-132, 1985.

[37] W. L. Healy, T. C. M. Lo, A. A. DiSimone, B. Rask, and B. A. Pfeifer, "Single-dose irradiation for the prevention of heterotopic ossification after total hip arthroplasty," The Journal of Bone \& Joint Surgery, vol. 77, no. 4, pp. 590-595, 1995.

[38] A. Konski, V. Pellegrini, C. Poulter et al., "Randomized trial comparing single dose versus fractionated irradiation for prevention of heterotopic bone: a preliminary report," International Journal of Radiation Oncology, Biology, Physics, vol. 18, no. 5, pp. 1139-1142, 1990.

[39] W. E. Drane, "Myositis ossificans and the three-phase bone scan," American Journal of Roentgenology, vol. 142, no. 1, pp. 179180,1984

[40] B. Schurch, M. Capaul, M. B. Vallotton, and A. B. Rossier, "Prostaglandin E2 measurements: their value in the early diagnosis of heterotopic ossification in spinal cord injury patients," Archives of Physical Medicine and Rehabilitation, vol. 78, no. 7, pp. 687-691, 1997.

[41] J. R. Sawyer, M. A. Myers, R. N. Rosier, and J. E. Puzas, "Heterotopic ossification: Clinical and cellular aspects," Calcified Tissue International, vol. 49, no. 3, pp. 208-215, 1991. 
[42] J. L. Tyler, V. Derbekyan, and R. Lisbona, "Early diagnosis of myositis ossificans with Tc-99m diphosphonate imaging," Clinical Nuclear Medicine, vol. 9, no. 5, pp. 256-258, 1984.

[43] M. H. Seegenschmiedt, P. Martus, A. R. Goldmann, R. W $\div$ lfel, L. Keilholz, and R. Sauer, "Preoperative versus postoperative radiotherapy for prevention of heterotopic ossification (HO): first results of a randomized trial in high-risk patients," International Journal of Radiation Oncology, Biology, Physics, vol. 30, no. 1, pp. 63-73, 1994.

[44] R. G. Slawson, A. Poka, H. Bathon, O. M. Salazar, R. J. Bromback, and A. R. Burgess, "The role of post-operative radiation in the prevention of heterotopic ossification in patients with post-traumatic acetabular fracture," International Journal of Radiation Oncology, Biology, Physics, vol. 17, no. 3, pp. 669-672, 1989.

[45] J. E. Sylvester, P. Greenberg, M. T. Selch, B. J. Thomas, and H. Amstutz, "The use of postoperative irradiation for the prevention of heterotopic bone formation after total hip replacement," International Journal of Radiation Oncology, Biology, Physics, vol. 14, no. 3, pp. 471-476, 1988.

[46] R. Brunner, E. Morscher, and R. Hünig, "Para-articular ossification in total hip replacement: An indication for irradiation therapy," Archives of Orthopaedic and Trauma Surgery, vol. 106, no. 2, pp. 102-107, 1987.

[47] D. C. Ayers, C. M. Evarts, and J. R. Parkinson, "The prevention of heterotopic ossification in high-risk patients by low-dose radiation therapy after total hip arthroplasty.," The Journal of Bone \& Joint Surgery, vol. 68, no. 9, pp. 1423-1430, 1986.

[48] S. J. Gregoritch, M. Chadha, V. D. Pelligrini, P. Rubin, and D. A. Kantorowitz, "Randomized trial comparing preoperative versus postoperative irradiation for prevention of Heterotopic ossification following prosthetic total hip replacement: Preliminary results," International Journal of Radiation Oncology, Biology, Physics, vol. 30, no. 1, pp. 55-62, 1994.

[49] T. C. M. Lo, W. L. Healy, D. J. Covall et al., "Heterotopic bone formation after hip surgery: Prevention with single-dose postoperative hip irradiation," Radiology, vol. 168, no. 3, pp. 851854, 1988.

[50] A. Sheybani, M. J. Tennapel, W. D. Lack et al., "Risk of radiationinduced malignancy with heterotopic ossification prophylaxis: a case-control analysis," International Journal of Radiation Oncology, Biology, Physics, vol. 89, no. 3, pp. 584-589, 2014.

[51] P. Kjaersgaard-Andersen, A. Nafei, G. Teichert et al., "Indomethacin for prevention of heterotopic ossification. A randomized controlled study in 41 hip arthroplasties," Acta Orthopaedica, vol. 64, no. 6, pp. 639-642, 1993.

[52] E. Elmstedt, T. S. Lindholm, O. S. Nilsson, and H. Törnkvist, "Effect of ibuprofen on heterotopic ossification after hip replacement," Acta Orthopaedica, vol. 56, no. 1, pp. 25-27, 1985.

[53] B. Sodemann, P.-E. Persson, and O. S. Nilsson, "Prevention of heterotopic ossification by nonsteroid antiinflammatory drugs after total hip arthroplasty," Clinical Orthopaedics and Related Research, no. 237, pp. 158-163, 1988.

[54] J. W. Pritchett, "Ketorolac prophylaxis against heterotopic ossification after hip replacement," Clinical Orthopaedics and Related Research, no. 314, pp. 162-165, 1995.

[55] D. Knelles, T. Barthel, A. Karrer, U. Kraus, J. Eulert, and O. Kölbl, "Prevention of heterotopic ossification after total hip replacement. A prospective randomised study using acetylsalicyclic acid indomethacin and fractional or single-dose irradiation," The Journal of Bone \& Joint Surgery, vol. 79, no. 4, pp. 596-602, 1997.
[56] E. E. Pakos, K. S. Stafilas, P. G. Tsekeris, A. N. Politis, G. Mitsionis, and T. A. Xenakis, "Combined radiotherapy and indomethacin for the prevention of heterotopic ossification after total hip arthroplasty," Strahlentherapie und Onkologie, vol. 185 , no. 8, pp. 500-505, 2009.

[57] J. Zacher, E. Walther, and A. Gursche, "OP0127 prevention of periarticular ossification (pao) after total hip replacement (thr) with rofecoxib 25 mg," Annals of the Rheumatic Diseases, vol. 60, supplement 1, 2001.

[58] H. J. L. Van Der Heide, W. J. Rijnberg, A. Van Sorge, A. Van Kampen, and B. W. Schreurs, "Similar effects of rofecoxib and indomethacin on the incidence of heterotopic ossification after hip arthroplasty," Acta Orthopaedica, vol. 78, no. 1, pp. 90-94, 2007.

[59] O. L. Bijvoet, A. J. Nollen, T. J. Slooff, and R. Feith, "Effect of a diphosphonate on para-articular ossification after total hip replacement," Acta Orthopaedica Scandinavica, vol. 45, no. 6, pp. 926-934, 1974.

[60] M. M. Ciccone, A. Aquilino, F. Cortese et al., "Feasibility and effectiveness of a disease and care management model in the primary health care system for patients with heart failure and diabetes (Project Leonardo)," Vascular Health and Risk Management, vol. 6, no. 1, pp. 297-305, 2010. 


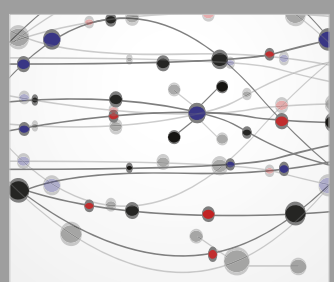

The Scientific World Journal
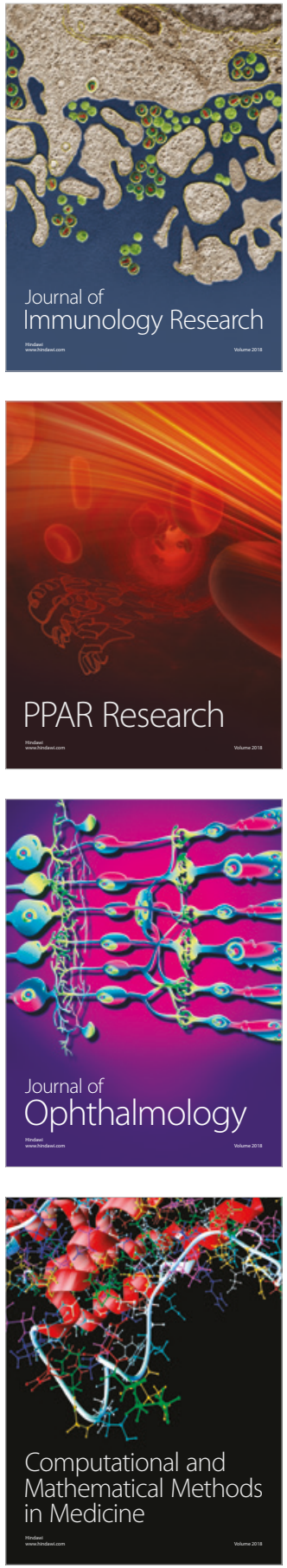

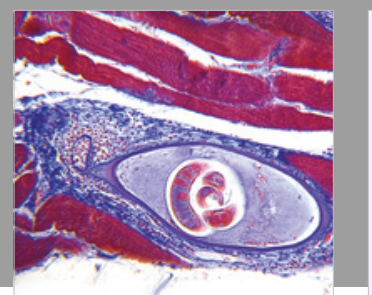

Gastroenterology Research and Practice

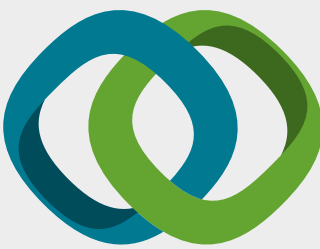

\section{Hindawi}

Submit your manuscripts at

www.hindawi.com
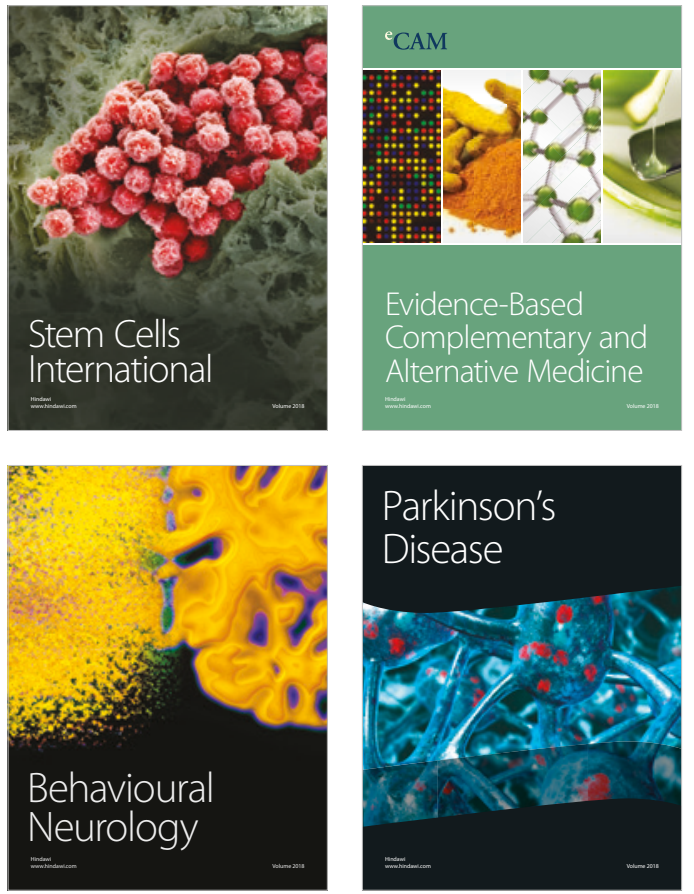

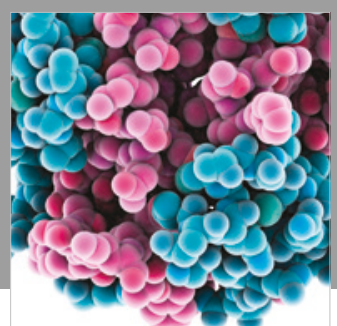

ournal of

Diabetes Research

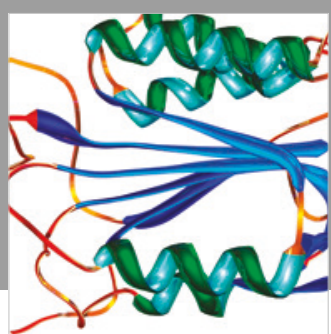

Disease Markers
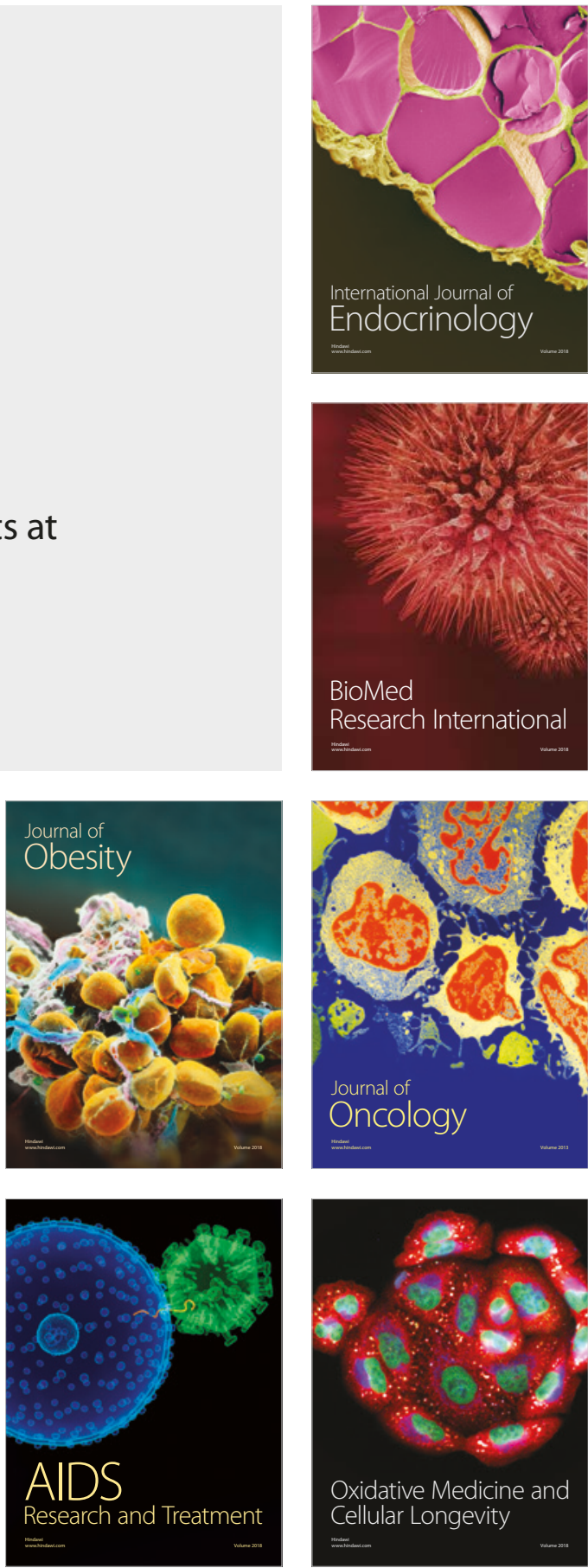